\title{
Effects of One Year Treatment of Sibutramine on Insulin Resistance Parameters in Type 2 Diabetic Patients
}

\author{
Giuseppe Derosa ${ }^{1}$, Pamela Maffioli ${ }^{1}$, Ilaria Ferrari ${ }^{1}$, Ilaria Palumbo ${ }^{1}$, Sabrina Randazzo ${ }^{1}$, Angela D’Angelo ${ }^{1}$, Arrigo FG \\ Cicero $^{2}$ \\ ${ }^{1}$ Department of Internal Medicine and Therapeutics, University of Pavia, Pavia, Italy \\ "“G. Descovich" Atherosclerosis Study Center, Department of Internal Medicine, Aging and Kidney diseases, \\ University of Bologna, Bologna; Italy
}

Received, May 13, 2010; Revised, August 30, 2010; Accepted, September 9, 2010; Published, September 10, 2010

ABSTRACT - Purpose. comparison of the effects of one year treatment with sibutramine comared
placebo on insulin resistance parameters, body weight, glycemic control, and lipid profile, in ype 2 diabetic
patients. Methods. two hundred and forty-six patients with uncontrolled type 2 diabetes mo us in therapy with different oral hypoglycemic agents or insulin were enrolled in this study and ando ise to take sibutramine $10 \mathrm{mg}$ or placebo for one year. We evaluated at baseline, and after 5,9 , and 12 nths thes parameters: homeostasis model assessment insulin resistance index (HON -IR), tinol bindin protein 4 (RBP-4), resistin, visfatin, and high sensitivity-C reactive protein (H $A$ P body ight, body in Index (BMI), glycated hemoglobin $\left(\mathrm{HbA}_{1 \mathrm{c}}\right)$, fasting plasma glucose $(\mathrm{F} / \mathrm{G})$, post prandial sma glucose (PPG), fasting plasma insulin (FPI), total cholesterol (TC), low den ty lipoprotein-chole ol (LDL-C), high density lipoprotein-cholesterol (HDL-C), and triglycerides (Tg Results. a faster deg case of HOMA-IR, resistin, and RBP-4 was recorded with sibutramine cempared to control group. We observed a significant decrease of Hs-CRP in both groups, and a faster in vement $\mathrm{HbA}_{1 \mathrm{c}}, \mathrm{FP} \mathrm{G}$ and PPG with sibutramine compared to the control group; furthermore we reco de decreaso Non, TC, LDL-C, body weight, and BMI in the sibutramine group, but the coltrols a Conclusions. sibutramine gave a faster improvement of insulin resistano arame ts and flycemic ontrol compared to placebo; furthermore sibutramine gave also an imp eme of liy a profile, and body weight.

\section{INTRODUCTIOI}

Overw $t$ and obesity an increasing health problems soc ted with cardi ascular disorders a prema e mortality (1). Weight loss is the reo hmende first step in managing car rovascula ke(2). Intensive programs aimed at ro ing cerories (3) intake and at increasing hysical ctivity (4) have clearly shown to rove the metabolic control of obese diabetic pulients. However, the behavioural approach is usually slow and not always sufficient to get the optimal targets of weight and metabolic control in obese diabetic patients and a pharmacological treatment has often to be planned in order to significantly and quickly reduce their high cardiovascular disease risk (5). Weight loss drugs added to conventional lifestyle changes may help to achieve and maintain adequate weight loss and improve insulin sensitivity. Currently, two molecules are licensed for use as antiobesity drugs: orlistat, a gastrointestinal lipase inhibitor, reduces weight by around $3 \mathrm{~kg}$ on average, and sibutramine, a monoamine-reuptake inhibitor, results in mean weight losses of 4 to $5 \mathrm{~kg}$ (6). Sibutramine hydrochloride monohydrate is a norepinephrine and serotonin reuptake inhibitor approved for the long-term management of obesity, in conjunction with a reduced calorie diet and behaviour modification, in patients unable to lose weight with diet and lifestyle changes alone. Sibutramine is rapidly metabolized by the hepatic cytochrome P450 system (CYP) generating two pharmacologic active metabolites which affect both food intake and energy expenditure (7).

The efficacy of sibutramine has been demonstrated in randomised trials in obese/overweight patients including those with type 2 diabetes mellitus (T2DM) (8-10). Furthermore, glycemic control was improved in randomised trials when sibutramine was added to diet and lifestyle advice for patients receiving conventional antidiabetic therapy (11). However preliminary data emerged from the SCOUT trial (12) showed that there was a $16 \%$ rise in the risk

Corresponding Author: Giuseppe Derosa, Department of Internal Medicine and Therapeutics, University of Pavia, Pavia, P.le C. Golgi, 2 - 27100 PAVIA, Italy. E-mail: giuseppe.derosa@unipv.it. 
of non-fatal myocardial infarction or stroke in people taking sibutramine and for this reason recently European regulators have suspended the marketing authorisation for sibutramine, and the US Food and Drug Administration has restricted its licence.

We conducted a study on sibutramine just before the withdrawal of sibutramine licence, evaluating sibutramine effects on different parameters; our primary endpoint was to evaluate sibutramine effect on insulin resistance parameters in type 2 diabetic patients, but we also evaluated body weight, glycemic and lipid profile, and the onset of adverse events.

\section{METHODS}

\section{Study design}

This multicenter, randomised, double-blind, controlled study was conducted in the Internal Medicine and Therapeutics Department at the University of Pavia (Pavia, Italy) the Internal Medicine, Aging and $\mathrm{K}$ ' ey $\mathrm{d}$ ases Department "G. Descovich" A rosc rosis Study Center, at the Nniversity (Bologna, Italy).

\begin{tabular}{|c|c|c|}
\hline & Control group & Sibutramine group \\
\hline & 121 & 125 \\
\hline F) & $60 / 61$ & $63 / 62$ \\
\hline s) & $53 \pm 6$ & $51 \pm 4$ \\
\hline & $23 / 21$ & $24 / 18$ \\
\hline $\mathrm{Cl}_{\mathrm{g}}$ & $4 \pm 1$ & $5 \pm 2$ \\
\hline eight & $1.70 \pm 0.05$ & $1.71 \pm 0.06$ \\
\hline comitant disease, n (\%) & $108(89.3)$ & $112(89.6)$ \\
\hline Hypertension & $92(85.2)$ & $96(85.7)$ \\
\hline Hypercholesterolemia & $36(33.3)$ & $39(34.8)$ \\
\hline Hypertriglyceridemia & $6(5.5)$ & $4(3.6)$ \\
\hline Combined dyslipidemia & $28(25.9)$ & $25(22.3)$ \\
\hline Concurrent medications, $\mathrm{n}(\%)$ & $109(90.1)$ & $114(91.2)$ \\
\hline$A C E-I$ & $28(25.7)$ & $30(26.3)$ \\
\hline$A R B s$ & $36(33.0)$ & $31(27.2)$ \\
\hline Calcium-antagonists & $19(17.4)$ & $24(21.0)$ \\
\hline$\beta$-blockers & $7(6.4)$ & $9(7.9)$ \\
\hline Diuretics & $22(20.2)$ & $18(15.8)$ \\
\hline Statins & $44(40.4)$ & $48(42.1)$ \\
\hline Fibrates & $12(11.0)$ & $10(8.8)$ \\
\hline Omega-3 & $10(9.2)$ & $14(12.3)$ \\
\hline Acetylsalicylic acid & $99(90.8)$ & $94(82.5)$ \\
\hline Ticlopidine & $10(9.2)$ & $7(6.1)$ \\
\hline
\end{tabular}

Data are expressed as means $\pm S D$ or $n$ and \%

Sm. st.: Smoking status; Diab. dur.: diabetes duration; ACE-I: angiotensin-converting enzyme-inhibitors; ARBs: angiotensin receptor blockers
The study protocol was approved at each site by institutional review boards and conducted in accordance with the Declaration of Helsinki and its amendments.

\section{Patients}

We enrolled 246 Caucasian type 2 diabetie patients aged $\geq 18$ of either sex (Tabl according to the ESC (European S riety Cardiology) and EASD (European Association fo the Study of Diabetes) Guider. criteria (2), obese (body mass index [Em/ $\geq \mathrm{kg} / \mathrm{L}^{2}$ ) (13), and with uncontr ed T2DM [glycate hemoglobin $(\mathrm{Hb} / \mathrm{c})>0 \%$ in $\mathrm{t}$ apy wi. different oral bup pglycen agents or in Suitable patients identific from review of case notes hd/or computerized nic registers, were conta $d$ by the investigaty in person or by teleph

Pa ts were ex luded if they had a history of had unstable or rapidly 4. ressive diabetic retinopathy, nephropathy, or neu iny; impaired hepatic, or renal function, or severe anemia. 
Patients with cardiovascular disease (CVD) (eg, New York Heart Association class I-IV congestive heart failure or a history of myocardial infarction or stroke) or past incidences of cerebrovascular conditions (stroke or TIA), history of coronary artery disease, congestive heart failure, tachycardia, peripheral arterial occlusive disease, arrhythmia were also excluded. Women who were pregnant or breastfeeding or who might become pregnant (due to inadequate contraceptive precautions). All patients provided written informed consent to participate.

At the beginning of the study and for all the observational period, patients were taking different antidiabetic drugs. The complete list of the antidiabetic drugs taken is reported in Table 2.

\section{Treatments}

Patients were divided in two groups and assigned to receive, as addition to their current antidiabetic therapy, either sibutramine $10 \mathrm{mg}$ (sibutramine group) or placebo (control group) for 12 months in a randomised, double-blind, controlled study. Both placebo, and sibutramine were supplied as identical-looking, opaque, white capsules in coded bottles to ensure the blind status of the study. Randomisation was performed by drawing of envelopes containing randomisation codes prepared by a statistician. A copy of the code was provided only to the person responsible for performing the statistical analysis. The code was only broken after database lock, but it could been broken for individual subjects in the event an emergency. Medication compliance was assessed by counting the number pills returned by patients at the time of a ir s cifi clinic visits. At baseline, we veighed pai ipants an gave each patient bo containing upply study medicotio for $t$ least 1 days. Throughout the study, we istructed patients to take th $\mathrm{r}$ first dose of new dication on the day after $t y$ were given the stud nedication.

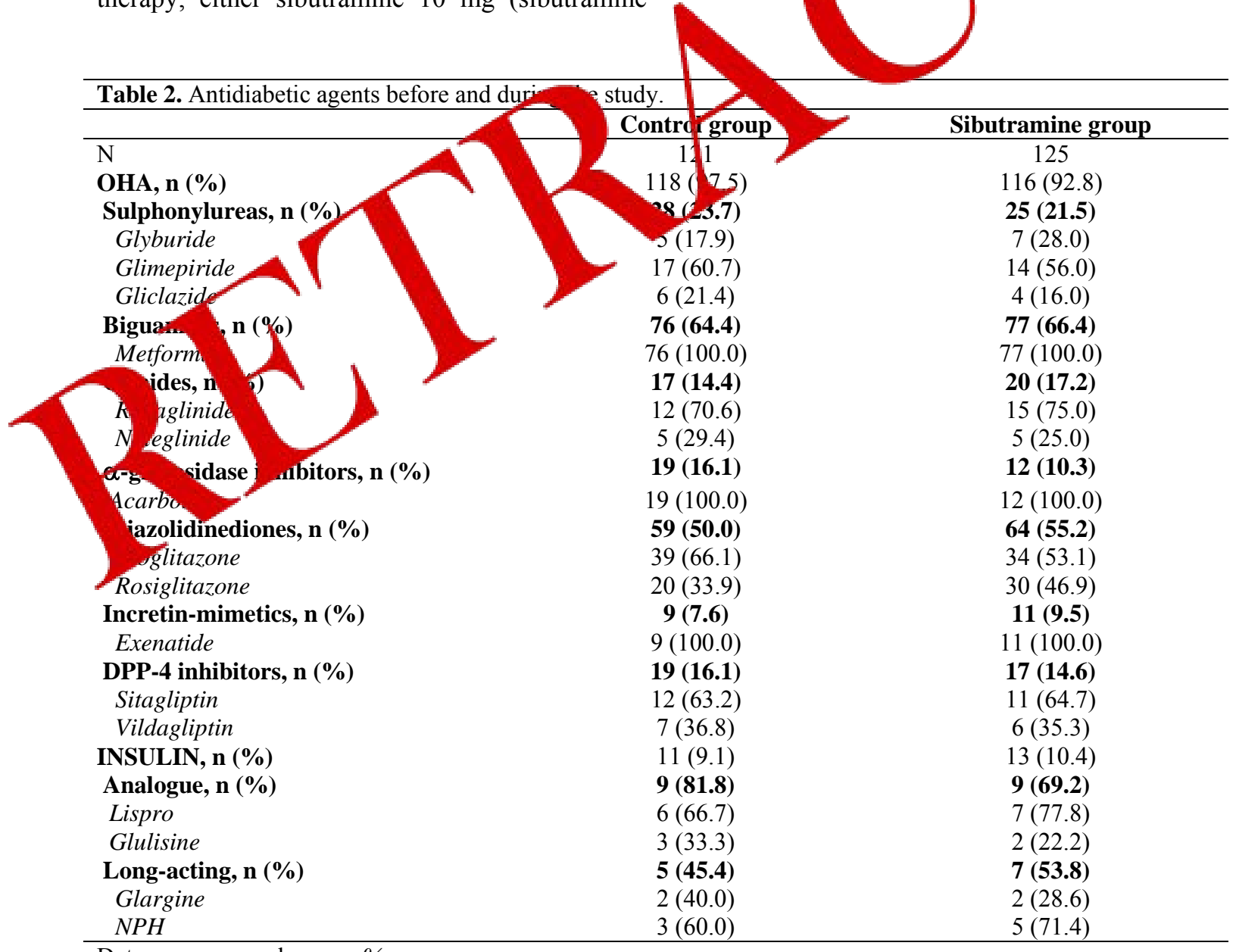

Data are expressed as $n$ or $\%$

OHA: oral hypoglycemic agents; DPP-4: dipeptidyl peptidase-4 inhibitors; NPH: neutral protamine Hagedorn 
A bottle containing placebo or the study medication for the next treatment period was given to participants each three months. At the same time, all unused medication was retrieved for inventory. Both placebo and medications were provided by each Hospital and were free of charge.

\section{Diet and Exercise}

Subjects began a controlled-energy diet (near 600 Kcal daily deficit) based on American Heart Association (AHA) recommendations (14) that included $50 \%$ of calories from carbohydrates, $30 \%$ from fat $(6 \%$ saturated), and $20 \%$ from proteins, with a maximum cholesterol content of $300 \mathrm{mg} /$ day and $35 \mathrm{~g} /$ day of fiber. Patients were not treated with vitamins or mineral preparations during the study.

Standard diet advice was given by a dietitian. Every three months a dietitian provided instruction on dietary intake recording procedures as part of a behaviour modification program and then later used the subject's food diaries for counselling. Individuals were also encouraged to increase their physical activity by wal- briskly for 20 to 30 minutes, 3 to 5 time er we or by cycling. The recommended han in nysical activity throughout the study we at each visit using the ubject's ac ty an Physical activity was o luated using he Borg RPE Scalenanmeasures ceived exer on (15).

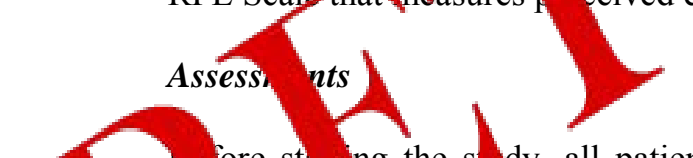

ore sta ng the s dy, all patients underwent initial s ening assessment that included a al hist , physical examination, vital signs, and a tead electrocardiogram. Blood pressure, nd vital sign measurements were assessed twice week for the first 12 weeks of treatment, and if there was a rise of $>10 \mathrm{mmHg}$, or heart rate $>10$ bpm or weight loss $>2 \mathrm{~kg}$ after 4 weeks treatment patients were discontinued from the study. We evaluated at baseline, and after 3, 6, 9, and 12 months these parameters: homeostasis model assessment insulin resistance index (HOMA-IR), retinol binding protein-4 (RBP-4), resistin, visfatin, and high sensitivity-C reactive protein (Hs-CRP), body weight, BMI, $\mathrm{HbA}_{1 \mathrm{c}}$, fasting plasma glucose (FPG), post-prandial plasma glucose (PPG), fasting plasma insulin (FPI), total cholesterol (TC), low density lipoproteincholesterol (LDL-C), high density lipoproteincholesterol (HDL-C), and triglycerides (Tg).
In order to evaluate the tolerability assessments, all adverse events were recorded. All plasmatic parameters were determined after a 12$h$ overnight fast, with the exception of PPG, determined 2 hours after a standardized meal. Venous blood samples were taken for all patients between 08.00 and 09.00. We used plasma obtained by addition of Na2-EDTA, $1 \mathrm{mg} / \mathrm{ml}$, and centrifuged at $3000 \mathrm{~g}$ for 15 minutes at $4^{\circ} \mathrm{C}$. Immediately after centrifugation, the plasma samples were frozen and stored at $-80^{\circ} \mathrm{C}$ for $n$ more than 3 months. All measurements ere performed in a central laboratory.

The HOMA-IR index was calculated as product of basal glucose (n / / l) and insuli levels $(\mu \mathrm{U} / \mathrm{ml})$ divided by $25(1 \quad 7)$

Retinol binding,

a retinol bindig p ein-4 (Hun $)$ EIA rit (Phoenix Phan aceutio Inc., Burl ene, CA, USA) The in ra- and is rassay Cs, were less than $.0 \%$ and less than $14 \%$, respectively (18). com rially value was measured by a imm issay (ELISA) kit (BioVendor Labora Monícine, Brno, Czech Republic). ra-assay $\mathrm{CsV}$ was $3.4 \%$ and inter-assay $\mathrm{CsV}$ $w_{c} \rho \%$, respectively (19).

Visfatin levels were measured by enzyme immunoassay (EIA) kit obtained from Phoenix Pharmaceuticals, Inc., (Burlingame, CA, USA). The intra- and interassay $\mathrm{CsV}$ were $10 \%$ and less than $14 \%$, respectively (20).

High sensitivity C-reactive protein was measured with use of latex-enhanced immunonephelometric assays on a BN II analyser (Dade Behring, Newark, Delaware, USA). The intra- and interassay $\mathrm{CsV}$ were $5.7 \%$ and $1.3 \%$, respectively (21).

Body mass index was calculated as weight in kilograms divided by the square of height in meters. Glycated hemoglobin level was measured by an HPLC method (DIAMAT, Bio-Rad, USA; normal values $4.2-6.2 \%$ ), with intra- and interassay $\mathrm{CsV}$ of $<2 \%$ (22). Plasma glucose was assayed by glucose-oxidase method (GOD/PAP, Roche Diagnostics, Mannheim, Germany) with intra- and interassay coefficients of variation of $<$ 2\% (23). Plasma insulin was assayed with Phadiaseph Insulin RIA (Pharmacia, Uppsala, Sweden) by using a second antibody to separate the free and antibody-bound 125 I-insulin (intraand interassay coefficients of variation: 4.6 and $7.3 \%$, respectively) (24).

Total cholesterol and $\mathrm{Tg}$ levels were determined using fully enzymatic techniques (25- 
26) on a clinical chemistry analyzer (HITACHI 737; Hitachi, Tokyo, Japan); intra- and interassay $\mathrm{CsV}$ were 1.0 and 2.1 for TC measurement, and 0.9 and 2.4 for $\mathrm{Tg}$ measurement, respectively. High density lipoprotein-cholesterol level was measured after precipitation of plasma apo Bcontaining lipoproteins with phosphotungstic acid (27) intra- and interassay $\mathrm{CsV}$ were 1.0 and 1.9, respectively; LDL-C level was calculated by the Friedewald formula (28).

\section{Statistical Analysis}

An intention-to-treat analysis was conducted in patients who had received $\geq 1$ dose of study medication and had a subsequent efficacy observation. Patients were included in the tolerability analysis if they had received $\geq 1$ dose of trial medication and had undergone a subsequent tolerability observation. Considering as clinically significant a difference of at least the $10 \%$ compared to the baseline and an alpha error of 0.05 , the actual sample size was adequate to obtain a power higher than 0.80 for all measured variable. Continuous variables were compared by analysis of variance (ANOVA). Inter tion effects were adjusted for addi 1 po tial confounders using analys of ove nnce (ANCOVA). ANOVA also used to ssess significance within and etween gro s. Tho statistical signifar ce of $t$ independen cfects of treatments on the o $r$ variables was deternm using ANCOVA. 1-sample t test was used co pare yalues o dined before and at treatn t admini tration; 2-sample t tests we used fo betwee -group comparisons (29). St 2 tical ana of data was performed using he Package for Social Sciences ftware version 11.0 (SPSS Inc., Chicago, 1 is, USA). Data are presented as mean \pm standard deviation (SD). For all statistical analyses, $\mathrm{p}<0.05$ was considered statistically significant.

\section{RESULTS}

\section{Study sample}

A total of 246 type 2 diabetic patients were enrolled in the study; of these, 24 patients did not complete the study and the reasons for premature withdrawal are explained in Figure 1. The characteristics of the patient population at study entry are shown in Table 1 .

\section{Insulin resistance parameters}

A statistically significant decrease of HOMA-IR was recorded after 9, and 12 months $(p<0.05$, and $\mathrm{p}<0.01$, respectively) compared to baseline in the group treated with sibutramine, and after 12 months $(\mathrm{p}<0.05)$ in the control group without any significant difference between the groups (Table 4, and Figure 2).

Retinol binding protein-4 value was significantly decreased after 9 , and 12 months $<0.05, \mathrm{p}<0.02$, respectively) comparea baseline in the group treated with and after 12 months in the con ol group. No differences were recorded between e two groups (Table 4, and Figure 2)

Resistin value significant decrease after 9 , and 12 onths $<0.05$, anc $<0$ ol, respectively mpared to aseline in group treated vith siburramine, a after 12 months in the co rol group $(\mathrm{p}<0.05)$. did not observe any nificant differences, between the two groups able 4 , and Figure 2).

We not observe any significant variation visfatin w. group and no differences were rea between the two groups (Table 4, and Figul 2).

\section{Inflammatory state}

A significant decrease of Hs-CRP value was obtained after 12 months in both groups $(\mathrm{p}<0.02$ with sibutramine, and $\mathrm{p}<0.05$ with placebo) compared to baseline without significant differences between the two groups (Table 4, and Figure 2).

\section{Body weight and BMI}

There was a significant decrease of body weight, and BMI after 9, and 12 months ( $<<0.05$, and $\mathrm{p}<$ 0.01 , respectively) in the sibutramine group, while no statistically significant variations of BMI and body weight were observed in the control group. Furthermore, the body weight value obtained with sibutramine was significantly lower than the value obtained in the control group after 9, and 12 months $(\mathrm{p}<0.05$, and $\mathrm{p}<0.01$, respectively). Moreover the BMI value recorded in the group treated with sibutramine was significantly lower than the value obtained in the control group after 12 months $(\mathrm{p}<0.05)$ (Table 3$)$. 


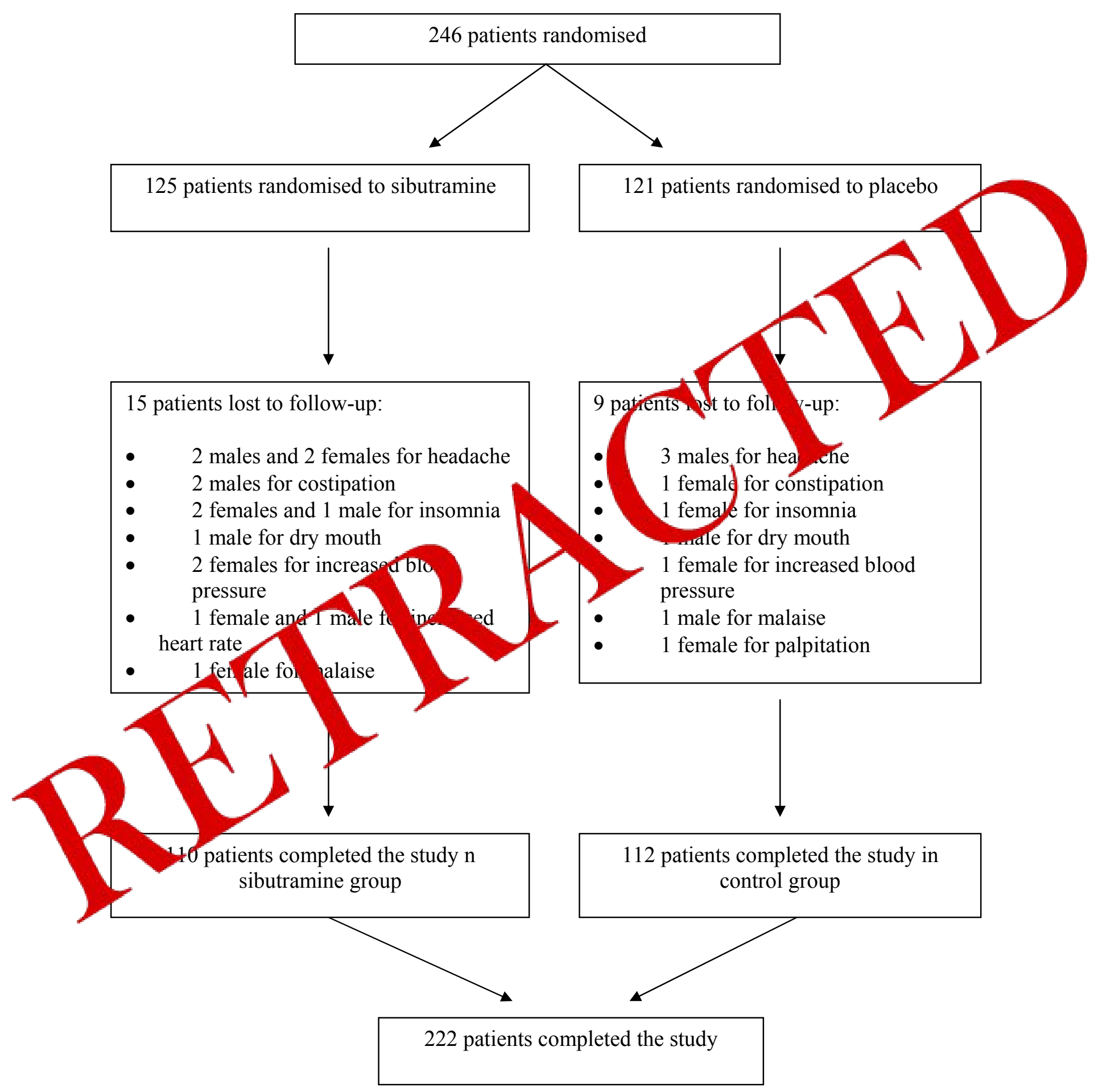

Figure 1. Study design 


\section{Glycemic parameters}

We observed a statistically significant improvement of $\mathrm{HbA}_{1 \mathrm{c}}$ after 9 and 12 months $(\mathrm{p}<$ 0.05 , and $p<0.01$, respectively) compared to baseline in the control group and after 6,9, and 12 months in the sibutramine group ( $<<0.05$, p $<$ 0.01 , and $\mathrm{p}<0.001$, respectively). We did not record any significant differences between the two groups (Table 3 ).

There was a statistically significant decrease of FPG after 12 months $(\mathrm{p}<0.05)$ compared to baseline in the control group and after 9 , and 12 months in the sibutramine group ( $\mathrm{p}<0.05$, and $\mathrm{p}$ $<0.01$ respectively). No differences between the two groups were recorded (Table 3 ).

A significant decrease of PPG was reported after 12 months $(p<0.05)$ compared to baseline in the control group and after 9 , and 12 months in the sibutramine group $(\mathrm{p}<0.05$, and $\mathrm{p}<0.01$ respectively). No differences between the two groups were obtained (Table 3 ).

There was a decrease of FPI after 12 months $(\mathrm{p}<0.05)$ compared to baseline in the group treated with sibutramine not obsery in the control group, even if we di ot re d any differences between the tw $\mathrm{rou}_{\mathrm{H}} \mathrm{Tab}, 4$, and Figure 2).

\section{Lipid profile}

A si ficant decrease of C, and LDL-C was observ afte 12 months (p .05, for both) with

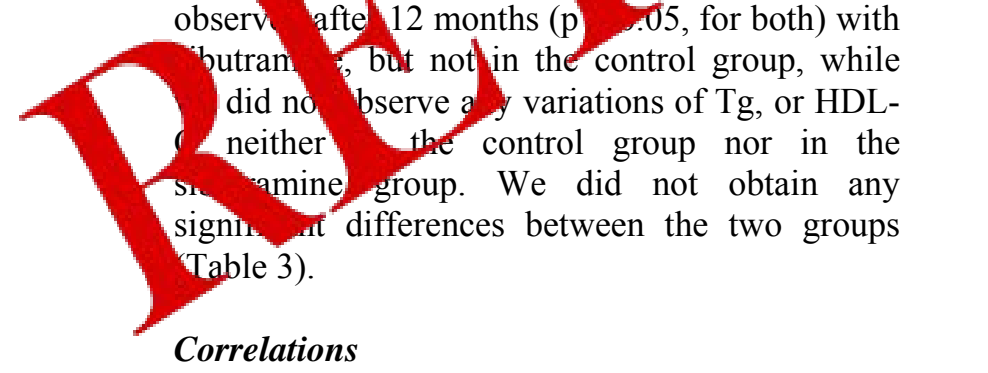

Stepwise multilinear regression analysis was undertaken to establish which anthropometric and metabolic factors could best predict the insulinresistance (HOMA) improvement changes or which metabolic factors could best predict the anthropometric (BMI) improvement change. Significant predictors of change in insulinresistance (HOMA) were RBP-4 and resistin concentration in sibutramine group $(\mathrm{r}=0.56, \mathrm{p}<$ 0.05 , and $\mathrm{r}=0.62, \mathrm{p}<0.01$, respectively), and significant predictors of change in anthropometric value (BMI) were RBP-4 and resistin concentration in sibutramine group $(\mathrm{r}=0.58, \mathrm{p}<$ 0.01 , and $\mathrm{r}=0.64, \mathrm{p}<0.01$, respectively).

\section{DISCUSSION}

We have already demonstrated in two our previous studies that sibutramine appears to be a tolerable and efficacious drug when added to pioglitazone for the global management of obese diabetic patients (30-31). Sibutramine appeared to give a better improvement of body ght compared to pioglitazone, while th o ts equally reduced blood pressures, impro glycemic control and HOr index. Bo pioglitazone and sibutranm ga a 7 LDI-C, and Tg decrease, yh no HDL-C riations y re observed (30)

In the nent stu we have $r$ cled that both acebo and sibutr ine added to the usual anti abetic therapy taken fore the beginning of the tudy, gave, a sim ar improvement of gly ic control, even if sibutramine addition gave faster improvement of glycemic parame n have also observed that utramine, but not placebo, gave an in vrement of lipid profile, even if, at the end of the study, no significant differences between the two groups were observed. Furthermore we confirmed that sibutramine gave an improvement of body weight, according to what previously reported by our group (30).

Regarding insulin resistance, it has been reported in literature that in T2DM patients the HOMA-IR resulted to be increased compared to the normal glucose tolerance (NGT) subjects (32) and that exercise training can improve insulin sensibility (33). Data from our study showed that sibutramine gave a faster improvement of FPI and HOMA-IR compared to placebo, confirming what already reported in literature (29-30).

Compared to our previous studies, we have also evaluated some insulin resistance parameters, such as RBP-4, resistin, and visfatin. Regarding RBP-4, its concentration has been reported to be increased in subjects with obesity, insulin resistance or T2DM compared with lean subjects (34), even if the mechanisms by which RBP-4 induces insulin resistance are not well understood. On the other side, resistin is produced by mononuclear cells and activated macrophages: it has been demonstrated that overexpression of resistin decreases the ability of insulin to suppress hepatic glucose output or increase glucose uptake by muscle (35-37). 
Table 3. Body weight, glycemic profile, and lipid profile data during the study.

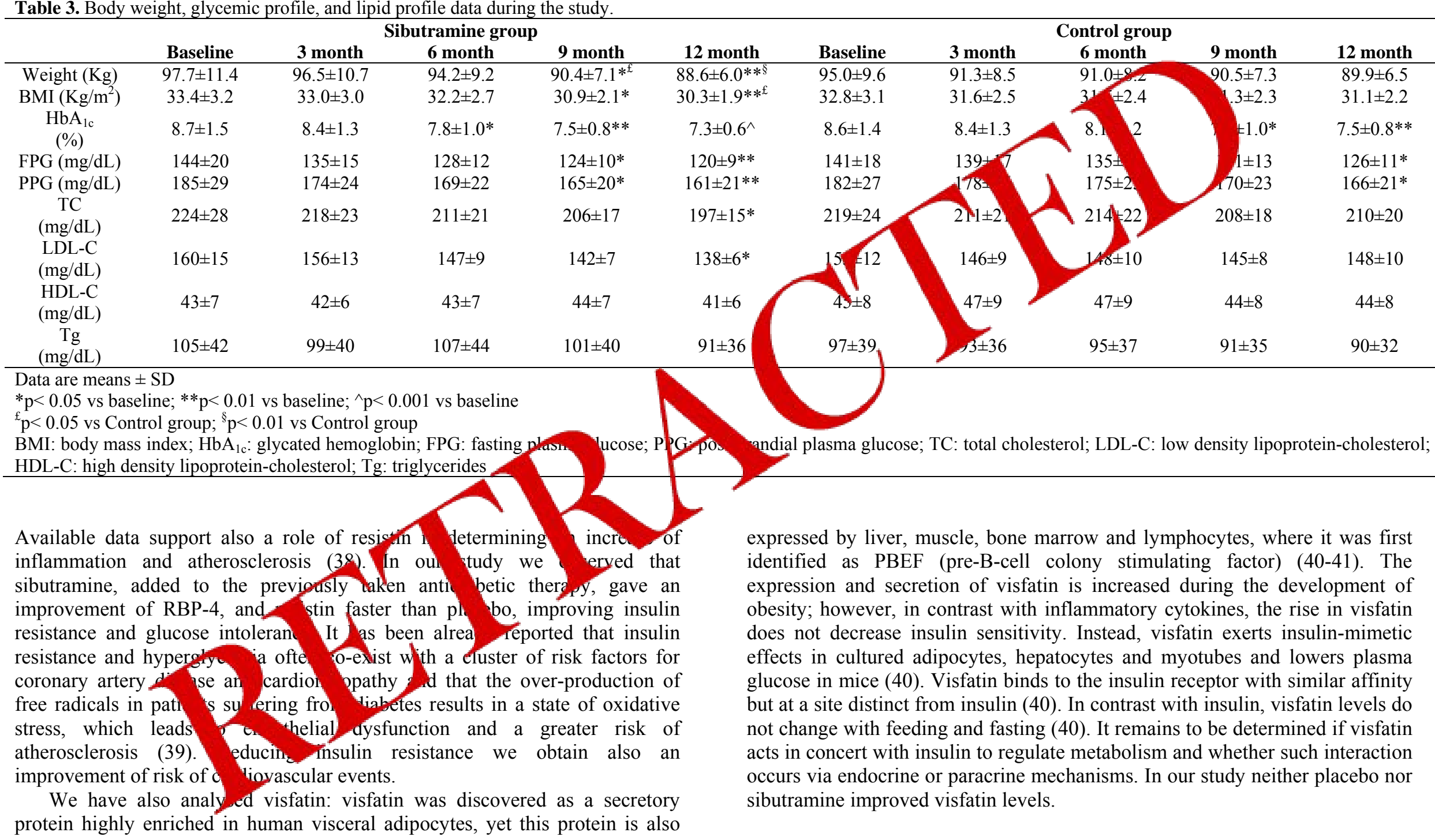


Table 4. Insulin resistance and inflammatory parameters during the study.

\begin{tabular}{|c|c|c|c|c|c|c|c|c|c|c|}
\hline & \multicolumn{5}{|c|}{ Sibutramine group } & \multicolumn{5}{|c|}{ Control groum } \\
\hline & Baseline & 3 month & 6 month & 9 month & 12 month & Baseline & 3 month & 6 month & 9 month & 12 month \\
\hline $\mathrm{n}$ & 125 & 119 & 116 & 112 & 110 & 121 & 117 & 5 & 114 & 112 \\
\hline $\begin{array}{c}\text { sex } \\
(\mathrm{M} / \mathrm{F})\end{array}$ & $63 / 62$ & $61 / 58$ & $59 / 57$ & $58 / 54$ & $56 / 54$ & $60 / 61$ & & & $57 / 57$ & $55 / 57$ \\
\hline $\begin{array}{l}\text { Sm. st. } \\
(\mathrm{M} / \mathrm{F})\end{array}$ & $24 / 18$ & $22 / 18$ & $21 / 18$ & $21 / 17$ & $21 / 17$ & $23 / 21$ & & & $21 / 21$ & $20 / 21$ \\
\hline $\begin{array}{c}\text { FPI } \\
(\mu \mathrm{U} / \mathrm{mL})\end{array}$ & $24.9 \pm 7.2$ & $24.0 \pm 6.8$ & $23.3 \pm 5.9$ & $22.4 \pm 5.4$ & $21.2 \pm 5.0 *$ & & & & $22.8 \pm 5.6$ & $22.5 \pm 5.5$ \\
\hline $\begin{array}{l}\text { HOMA- } \\
\text { IR }\end{array}$ & $8.9 \pm 5.1$ & $8.0 \pm 4.5$ & $7.4 \pm 4.1$ & $6.9 \pm 3.6^{*}$ & $6.3 \pm 3.5^{* *}$ & & & & $7.4 \pm 4.1$ & $7.1 \pm 3.8^{*}$ \\
\hline $\begin{array}{l}\text { RBP-4 } \\
(\mu \mathrm{g} / \mathrm{mL})\end{array}$ & $43.9 \pm 11.8$ & $41.4 \pm 10.2$ & $37.6 \pm 9.4$ & $36.4 \pm 9.0^{*}$ & $35.0 \pm 8.6^{\$}$ & $41.6 \pm 10.3$ & & $38.7 \pm 9.6$ & $37.1 \pm 9.1$ & $35.8 \pm 8.9^{*}$ \\
\hline $\begin{array}{l}\text { Resistin } \\
\text { (ng/mL) }\end{array}$ & $7.1 \pm 2.5$ & $6.9 \pm 2.3$ & $6.4 \pm 1.9$ & $6.0 \pm 1.7^{*}$ & $5.5 \pm 1.5 * *$ & $6.9 \pm 2.3$ & \pm 2.2 & $6.5 \pm 2.0$ & $6.4 \pm 1.9$ & $6.2 \pm 1.8^{*}$ \\
\hline $\begin{array}{l}\text { Visfatin } \\
\text { (ng/mL) }\end{array}$ & $17.9 \pm 6.5$ & $16.9 \pm 6.0$ & $16.6 \pm 5.8$ & $16.5 \pm 5.7$ & & & $17.3 \pm 6.1$ & $17.5 \pm 6.2$ & $16.9 \pm 6.0$ & $16.7 \pm 5.9$ \\
\hline $\begin{array}{l}\text { Hs-CRP } \\
(\mathrm{mg} / \mathrm{L})\end{array}$ & $2.6 \pm 1.8$ & $2.2 \pm 1.4$ & $2.1 \pm 1.3$ & & & $2.4 \pm 1.6$ & $2.3 \pm 1.5$ & $2.2 \pm 1.4$ & $2.1 \pm 1.3$ & $1.9 \pm 1.2^{*}$ \\
\hline
\end{tabular}

Regarding inflammatory prameters, Hs-CK has beeh shown to independently predict myocar infarction, stroke nd peripheral artery disease (42-43). In our study b s utramine and pracebo improved this parameter.

Regarding adv e read ons we not ob orve any significant differences between the group th thed sibutra and the group treated with placebo; the reported adverse o cts th headache, constipation, insomnia, dry mouth, increased blood pressul increasud heart rate, depression, malaise, palpitation. All the events were repo 1 as mild or moderate. This was in line with what already reported by ou group in two previous studies (44-45); sibutramine intake was not associated to any cardiovascular effects and was generally well tolerated.
This was in contrast with what recently reported by unpublished data from the sibutramine cardiovascular outcomes trial (SCOUT) (12). This six year trial of 10000 mostly European patients, which began in December 2002, showed a $16 \%$ rise in the risk of non-fatal myocardial infarction or stroke in people taking sibutramine. We think that the reason of these differences between our results in adverse effects and SCOUT results is that patients enrolled in the SCOUT trial had a history of cardiovascular disease and diabetes, and that $90 \%$ of these patients would not have been eligible for sibutramine under the current label.

The controversity between our study and the SCOUT trial is similar to the one reported on the clinical use of sulfonylurea, tolbutamide, on cardiovascular disease reported in 1970 by University Group Diabetes Programme (UGDP) (46). 


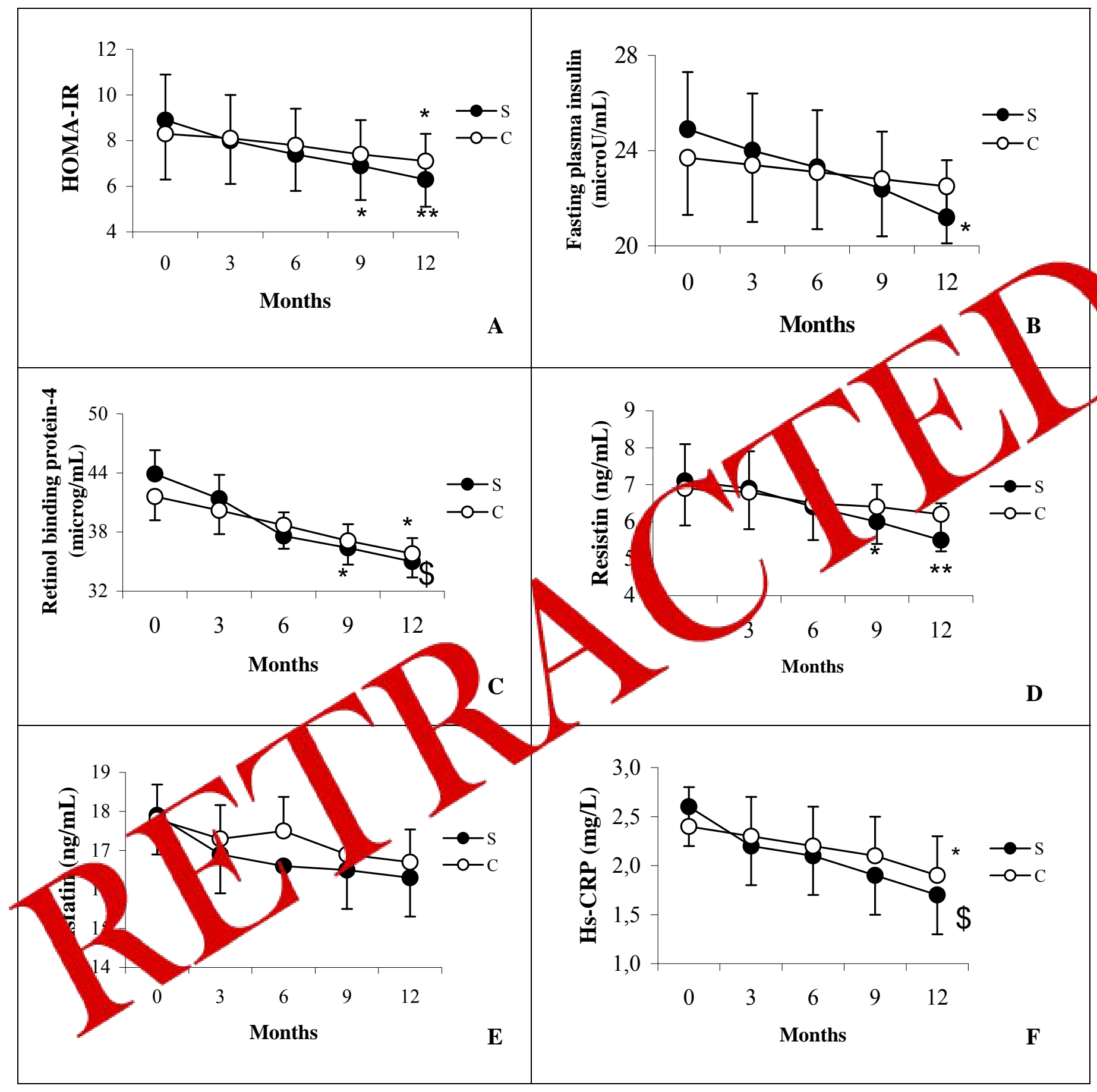

Figure. 2. Inflammatory and insulin resistance parameters variations during the study $* \mathrm{p}<0.05$ vs baseline; ${ }^{\$} \mathrm{p}<0.02$ vs baseline; ${ }^{*} \mathrm{p}<0.01$ vs baseline HOMA-IR: homeostasis model assessment insulin resistance index; FPI: fasting plasma insulin; RBP-4: retinol binding protein-4; Hs-CRP: high sensitivity-C reactive protein.

The study found cardiovascular disease mortality was higher in patients given tolbutamide than those given insulin (12.7\% vs $6.2 \%)$. These findings remained in controversy as United Kingdom Prospective Study (UKDPS 33 \& 34)
(47) showed reduction in cardiovascular effects of sulfonylureas.

Of course our study has some limitations: for example we did not evaluate if the beneficial effects on glycemic control, body weight, lipid 
profile and insulin resistance parameters were sustained after the cessation of therapy. Another limitation is that we evaluated only a limited number of insulin resistance biomarkers, more parameters should be considered to evaluated an effective improvement of insulin resistance.

However, at the best of our knowledge, this is the first study investigating the effect of sibutramine on insulin resistance and inflammatory parameters.

\section{CONCLUSIONS}

All data considered we can safely conclude that sibutramine gave a faster improvement of glycemic control and of insulin resistance parameters compared to placebo. Sibutramine gave also an improvement of lipid profile, and body weight not observed with placebo.

\section{AKNOWLEDGEMENTS}

The authors certify that have no affiliation with, or financial involvement in, any organization or entity with a direct financial interest in the subject matter or materials discussed in the manusu

\section{REFERENCES}

1. Van Gaal LF Mert Mechanism lin ing obc disease. Nature 2006; 444:

2. Rye Standl E, Bartnik Van den Berghe G, Better e J, le Boer MJ, Co tno F, Jönsson B, Laakso Malmbert K, Priori S, Ostergren J, uomile J, Thra sdottir I, Vanhorebeek I, stramba-B ale N, Lindgren P, Qiao Q, Priori Blanc J oudaj A, Camm J, Dean V, Deckers J, Ł stein K, Lekakis J, McGregor K, Metra M, Morais J, Osterspey A, Tamargo J, Zamorano JL, Teckers JW, Bertrand M, Charbonnel B, Erdmann E, Ferrannini E, Flyvbjerg A, Gohlke H, Juanatey JR, Graham I, Monteiro PF, Parhofer K, Pyörälä K, Raz I, Schernthaner G, Volpe M, Wood D; Task Force on Diabetes and Cardiovascular Diseases of the European Society of Cardiology (ESC); European Association for the Study of Diabetes (EASD). Guidelines on diabetes, prediabetes, and cardiovascular diseases: executive summary. The Task Force on Diabetes and Cardiovascular Diseases of the European Society of Cardiology (ESC) and of the European Association for the Study of Diabetes (EASD). Eur Heart J 2007; 28: 88-136.

3. American Diabetes Association. Physical Activity/Exercise and Diabetes. Diabetes Care 2004; 27: 58-62.
4. Lee M, Aronne LJ. Weight management for type 2 diabetes mellitus: global cardiovascular risk reduction. Am J Cardiol 2007; 99: 68B-79B.

5. Bolen S, Feldman L, Vassy J, Wilson L, Yeh HC, Marinopoulos S, Wiley C, Selvin E, Wilson R, Bass EB, Brancati FL. Systematic review: comparative effectiveness and safety of oral medications for type 2 diabetes mellitus. Ann Intern Med 2007; 147: 386-399.

6. Padwal RS, Majumdar SR. Drug treatments for obesity: orlistat, sibutramine, and rimonabant. Lancet 2007; 369: 71-77.

7. Arterburn DE, Crane PK, Veenstra DL. efficacy and safety of sibutramine for wht los a systematic review. Arch Intern Med 2004; 164. 994-1003.

8. James WP, Astrup Kopelman P, Rössne Effect of sibutranine weight loss a randon d trial. STC M Stady Group. Sibu amine Tr of Obesity eduction and Maintenance. Lancet - 0; 356: 2119-2125.

9. W den TA, Berkowitz R tomble LG, Sarwer DI Phelan S, Cato RK, nesson LA, Osei SY, $\mathrm{Ka} n \mathrm{R}$, Stunkdrd AJ. Randomized trial of lifes modification and pharmacotherapy for obesity Med 2005; 353: 2111-2120.

viner N, Bloom SR, Frost GS, Banks LM, ths J. Sibutramine is effective for weight loss 2nd diabetic control in obesity with type 2 diabetes: a randomised, double-blind, placebocontrolled study. Diabetes Obes Metab 2000; 2: 105-112.

11. Finer N, Ryan DH, Renz CL, Hewkin AC. Prediction of response to sibutramine therapy in obese non-diabetic and diabetic patients. Diabetes Obes Metab 2006; 8: 206-213.

12. Caterson I, Coutinho W, Finer N, Van Gaal L, Maggioni A, Torp-Pedersen C, Sharma AM, Ge H, Santoro D, Shepherd G, James P; SCOUT Investigators. Early response to sibutramine in patients not meeting current label criteria: preliminary analysis of SCOUT lead-in period. Obesity 2010; 18: 987-994.

13. World Health Organization. Obesity: preventing and managing the global epidemic. Report of WHO consultation on obesity. Geneva: WHO; 1997.

14. Lichtenstein AH, Appel LJ, Brands M, Carnethon M, Daniels S, Franch HA, Franklin B, KrisEtherton P, Harris WS, Howard B, Karanja N, Lefevre M, Rudel L, Sacks F, Van Horn L, Winston M, Wylie-Rosett J. Summary of American Heart Association Diet and Lifestyle Recommendations Revision 2006. Arterioscler Thromb Vasc Biol 2006; 26: 2186-2191.

15. Borg G. Perceived exertion as an indicator of somatic stress. Scand J Rehabil Med 1970; 2: 9298. 
16. Matthews DR, Hosker JP, Rudenski AS, Naylor BA, Treacher DF, Turner RC. Homeostasis model assessment: insulin resistance and beta-cell function from fasting plasma glucose and insulin concentrations in man. Diabetologia 1985; 28: 412-419.

17. Wallace TM, Levy JC, Matthews DR. Use and abuse of HOMA modeling. Diabetes Care 2004; 27: 1487-1495.

18. Takebayashi K, Suetsugu M, Wakabayashi S, Aso $\mathrm{Y}$, Inumai $\mathrm{T}$. Retinol binding protein-4 and clinical features of type 2 diabetes patients. J Clin Endocrinol Metab 2007; 92: 2712-2719.

19. Yannakoulia $M$, Yiannakouris $N$, Bluher $S$, Matalas AL, Klimis-Zacas D, Mantzoros CS. Body fat mass and macronutrient intake in relation to circulating soluble leptin receptor, free leptin index, adiponectin, and resistin concentrations in healthy humans. J Clin Endocrinol Metabol 2003; 88: 1730-1736.

20. Korner A, Garten A, Bluher M, Tauscher R, Kratzsch J, Kiess W. Molecular characteristics of serum visfatin and differential detection by immunoassays. J Clin Endocrinol Metab 2007; 92: 4783-4791.

21. Rifai N, Tracy RP, Ridker PM. Clinical Efficacy of an Automated High-Sensitivity C-Reactive Protein Assay. Clin Chem 1999; 45(12): 21362141.

22. Bunn HF, Gabbay KH, Gallop The glycosylation of haemoglobin Releva to diabetes mellitus. Science 1978;20 21-27.

23. European Diabetes Policy Grouk. A kte ide to type 2 diabetes me is. Diabet M 1999,
$716-730$.

24. Heding LG geterminati of total seru moulin (IRI) in insulin-treate diabetic patients. Dice logia 1972; 8: 260-2

25. Klose Bo ner K. Enzym othe Bestimmung des Ge tcholesterins mit aem Greiner Selective nalyze GSA II). Clin Chem Clin Biochem 1978; 15: hlefeld Methods of Enzymatic Analysis: Th. merices determination after enzymatic hydrorysis, 2nd English ed, Academic Press, Inc, vew York; 1974: 18-31.

21. Havel RJ, Edr HA, Bragdon JH. The distribution and chemical composition of ultracentrifugally separated lipoproteins in human serum. J Clin Invest 1955; 34: 1345-1353.

28. Friedewald WT, Levy RI, Fredrickson DS. Estimation of the concentration of low density lipoprotein in plasma, without use of the preparative ultracentrifuge. Clin Chem 1972; 18 : 499-502.

29. Winer BJ. Statistical Principles in Experimental Design. 2nd ed, McGraw-Hill, New York, 1971.

30. Derosa G, D'Angelo A, Salvadeo SAT, Ferrari I, Gravina A, Fogari E, Maffioli P, Cicero AFG. Sibutramine effect on metabolic control of obese patients with type 2 diabetes mellitus treated with pioglitazone. Metabolism 2008; 57: 1552-1557.

31. Derosa G, Mereu R, Salvadeo SAT, D'Angelo A, Ciccarelli L, Piccinni MN, Ferrari I, Gravina A, Maffioli P, Cicero AFG. Pioglitazone metabolic effect in metformin-intolerant obese patients treated with sibutramine. Inter Med 2009; 48: 265 271.

32. Li YB, Zhu DL, Tian HM, Shi LX, Luo ZJ, Yan L, Zeng LY, Zhou ZG, Yang LY, Liu J, Li M, Weng JP. Characteristics of dysfunction of islet beta-cell in newly diagnosed type 2 diabetic patients. Zhonghua Yi Xue Za Zhi 2006; 86: 2537 2541.

33. Qiu S, Wu C, Lin F, Chen L, Huang Z, Jiang Exercise training improved insulin senon vity a ovarian morphology in rats with rolycystic ovary syndrome. Horm Metab Res 260 1: 880-885.

34. Cho YM, Youn BS, Lee r, ee N Yin S, Kwak $\mathrm{SH}$, Lee HK, Park KS. Plasma nol-bindin protein-4 concentrat s are elevat in humz subjects with npaired ucose toleran and lype 2 diabetes. D abetes Car 006; 29: $245 \angle 461$.

35. Ste pan CM, Bailey S Bhat S, Brown EJ, Be erjee RR, Wright CM, tet HR, Ahima RS, Le $r$ MA. The hormone jesistin links obesity to dic tes. Nature (London) 2001; 409: 307-312.

36. Sat Nguyen MT, Miles PD, Imamura T, Usui I and, $1 M$. Adenovirus-mediated chronic 'hyper-resistinemia' leads to in vivo insulin ance in normal rats. J Clin Invest 2004; 114 : 24-231.

37. Rangwala SM, Rich AS, Rhoades B, Shapiro JS, Obici S, Rossetti L, Lazar MA. Abnormal glucose homeostasis due to chronic hyperresistinemia. Diabetes 2004; 53: 1937-1941.

38. Reilly MP, Lehrke M, Wolfe M, Rohatgi A, Lazar MA, Rader DJ. Resistin is an inflammatory marker of atherosclerosis in humans. Circulation 2005; 111: 932-939.

39. Sharma AK, Srinivasan BP. Triple verses glimepiride plus metformin therapy on cardiovascular risk biomarkers and diabetic cardiomyopathy in insulin resistance type 2 diadetes mellitus rats. Eur J Pharm Sci 2009; 38: 433-444.

40. Fukuhara A, Matsuda M, Nishizawa M, Segawa K, Tanaka M, Kishimoto K, Matsuki Y, Murakami M, Ichisaka T, Murakami H, Watanabe E, Takagi T, Akiyoshi M, Ohtsubo T, Kihara S, Yamashita S, Makishima M, Funahashi T, Yamanaka S, Hiramatsu R, Matsuzawa Y, Shimomura I. Visfatin: a protein secreted by visceral fat that mimics the effects of insulin. Science 2005; 307: 426-430.

41. Hug C, Lodish HF. Visfatin: a new adipokine. Science 2005; 307: 366-367.

42. Zwacka TP, Hornbach V, Torzewski J. C-reactive protein-mediated lipoprotein uptake by macrophages. Circulation 2001; 103: 1194-1197. 
43. Andersen K, Pedersen BK. The role of inflammation in vascular insulin resistance with focus on IL-6. Horm Metab Res 2008; 40: 635639.

44. Derosa G, Cicero AFG, Murdolo G, Piccinni MN, Fogari E, Bertone G, Ciccarelli L, Fogari R. Efficacy and safety comparative evaluation of orlistat and sibutramine treatment in hypertensive obese patients. Diabetes Obes Metab 2005; 7: 4755.

45. Derosa G, Cicero AF, Murdolo G, Ciccarelli L, Fogari R. Comparison of metabolic effects of orlistat and sibutramine treatment in Type 2 diabetic obese patients. Diabetes Nutr Metab 2004; 17: 222-229.

46. Pogátsa G. What kind of cardiovascular alteran could be influenced positively by oral tidiabe agents? Diabetes Res Clin Pract 1996; 31: S27-31

47. Holman RR, Paul SK, Bethel Matthews DR, Neil HA. 10-Year Follow of nsiy Glucose Control in Type 2 Dirbetes. N En. Med 200\%; 359 (15): 1577-1589

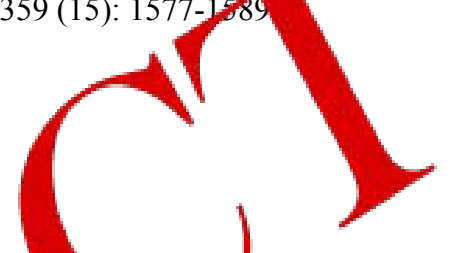

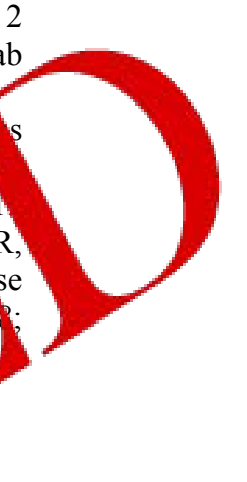

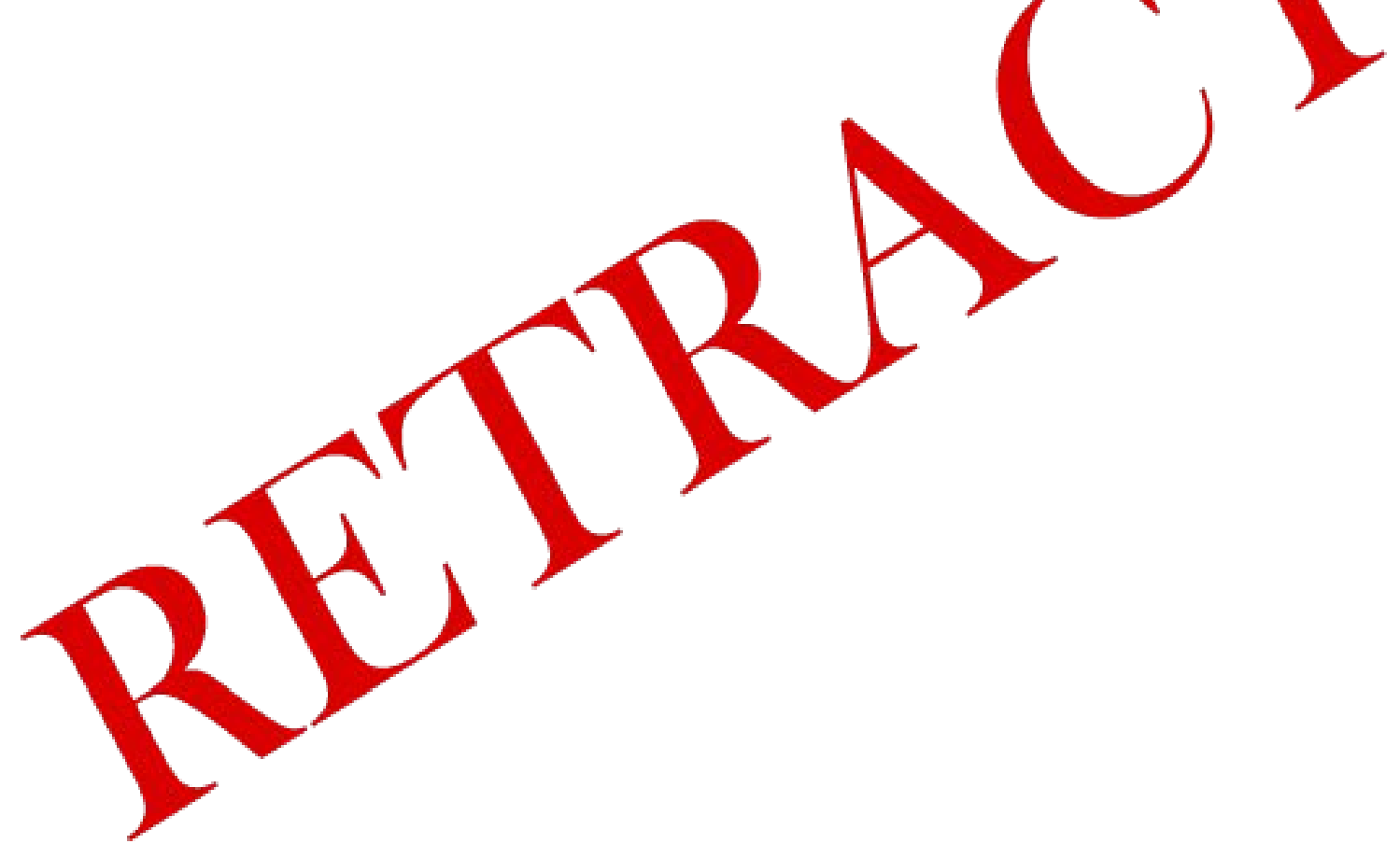

